\title{
Study on Optimal Design Method of Urban Sewage Collection Network Layout
}

\author{
Jiandong Tian*, Guifang He \\ Suzhou Vocational Institute of Industrial Technology, Jiangsu, China, 215104
}

Received: 23 September 2021

Accepted: 24 October 2021

\begin{abstract}
It is important to optimize the design of urban sewage collection pipe networks. In this study, we established a nonlinear programming mathematical model by considering the undetermined engineering system for an urban sewage collection pipe network scheme as the research subject. The model treats the minimum total annual cost of sewage collection pipe networks as the objective function, the head loss at the head and end of the branch and trunk pipes belonging to the trunk pipe section as the coupling constraint, the longitudinal slope of the pipe section, pipe economic flow rate, and optional standard pipe diameter of the division pipe section as the feasible region constraints on the decision variables, and the line scheme for the pipe networks and diameter of the division pipe section as decision variables. We developed an optimization method by combining orthogonal test-based line selection and the decomposition-dynamic programming aggregation method for the large diameter pipe system, which treats the branch and trunk pipes belonging to the trunk pipe section as the test factor, and the line scheme for the branch and trunk pipes belonging to the trunk pipe section as the test level. We considered the regional sewage collection pipe network in Taizhou city as an example to conduct a comparative analysis and verified that the proposed optimization method can solve this type of large system optimization problem rapidly and accurately, thereby providing a theoretical reference for optimizing the design of urban rainwater drainage pipe networks.
\end{abstract}

Keywords: dynamic programming, decomposition-aggregation, orthogonal test, pipe network

\section{Introduction}

Urbanization has accelerated since the start of this millennium due to China's rapid economic growth and sharp population increase, but the urban sewage collection pipe network restricts the economic prosperity of cities and severely affects the living environments of

*e-mail: tjd168@163.com urban residents. Thus, it is important to optimize urban sewage collection pipe networks.

Many previous studies have optimized the design of urban sewage collection pipe networks. In particular, Ali et al. established an integrated model for optimizing the engineering design of sewage collection pipe networks, which treated the allowable head loss as a constraint, the layout generation and parameters of sewer specifications as decision variables, and the sewage collection pipe network construction cost as the objective function. They designed the layout structure 
using the loop-by-loop cutting algorithm to optimize the cost function and the tabu search method as a deterministic combination metaheuristic algorithm in the context of the given layout to adaptively search the feasible region of decision variables, where they simultaneously solved two subproblems related to layout generation and sewer size [1]. Karovic et al. proposed a Microsoft Excel-based simulated annealing optimization design program to solve the rainwater pipeline system optimization design model. This model considered the hydraulics, technical standards, and regional limitations as constraints, the layout and pipe diameter of pipe networks as decision variables, and the total construction cost of the rainwater pipe system as the objective function [2]. Zhao et al. designed the preliminary pump parameters based on the pump design specifications and then established a mathematical model of the optimal design parameters combined with pump impellers based on the orthogonal test-based optimization method. The pump performance was improved significantly using this method, where the simulated head and efficiency were boosted [3]. Several previous studies employed the ACOA to optimize the construction cost of sewage collection pipe networks in order to obtain the optimal layout and optimal pipe diameter of pipe networks. In this paper, we consider constraints such as the construction cost and operation cost for urban sewage collection pipe networks, the head loss at the head and end of the pipe section, and the economic flow rate in the pipe section. Furthermore, we developed an optimization method that combines orthogonal test optimization with a selection method for the pipe network line scheme and the decompositiondynamic programming aggregation method for a large diameter pipe system, thereby obtaining a novel optimization design method for urban rainwater drainage pipe networks.

\section{Material and Methods}

In the present study, we aimed to solve the optimization design problem for pipe networks while focusing on the line scheme for sewage collection pipe networks [4-5].

A sewage collection pipe network is divided into $N$ trunk pipe sections. The trunk pipe section $i M_{i}$ receives the sewage from the trunk pipe section (i-1) $M_{(i-1)}$ but also the sewage flow $\sum_{j=1}^{M_{i}} q_{i j}$ collected by $M_{i}(i$ $=1,2, \ldots, N)$ sewage collection wells converging in this trunk pipe section. The pipe section $i j$ has $k$ types of line schemes available with lengths of $l_{i j k}(i=1,2, \ldots, N$; $\left.j=1,2, \ldots, M_{i} ; k=1,2, \ldots, K_{i j}\right)$. Finally, the sewage is transported by the trunk pipe section $N M_{N}$ to the main sewage collection pipe [6]. A generalized diagram illustrating the multi-line schemes in urban sewage collection pipe networks is shown in Fig. 1.

\section{Mathematical Model}

\section{Establishment of a Subsystem Model for Optimizing the Design of Sewage Collection Pipe Networks}

Annual cost objective function for the branch and trunk pipes belonging to the $i$-th pipe section of sewage collection pipe networks [7].

The minimum annual cost of sewage collection pipe networks is treated as the objective function. The annual cost of sewage collection pipe networks generally includes three components [8]: the annual investment cost of the pipe network construction, annual maintenance cost, and annual management cost. The annual cost of sewerage wells accounts for a small proportion of the annual cost of sewerage pipe networks, so it is directly incorporated into the annual

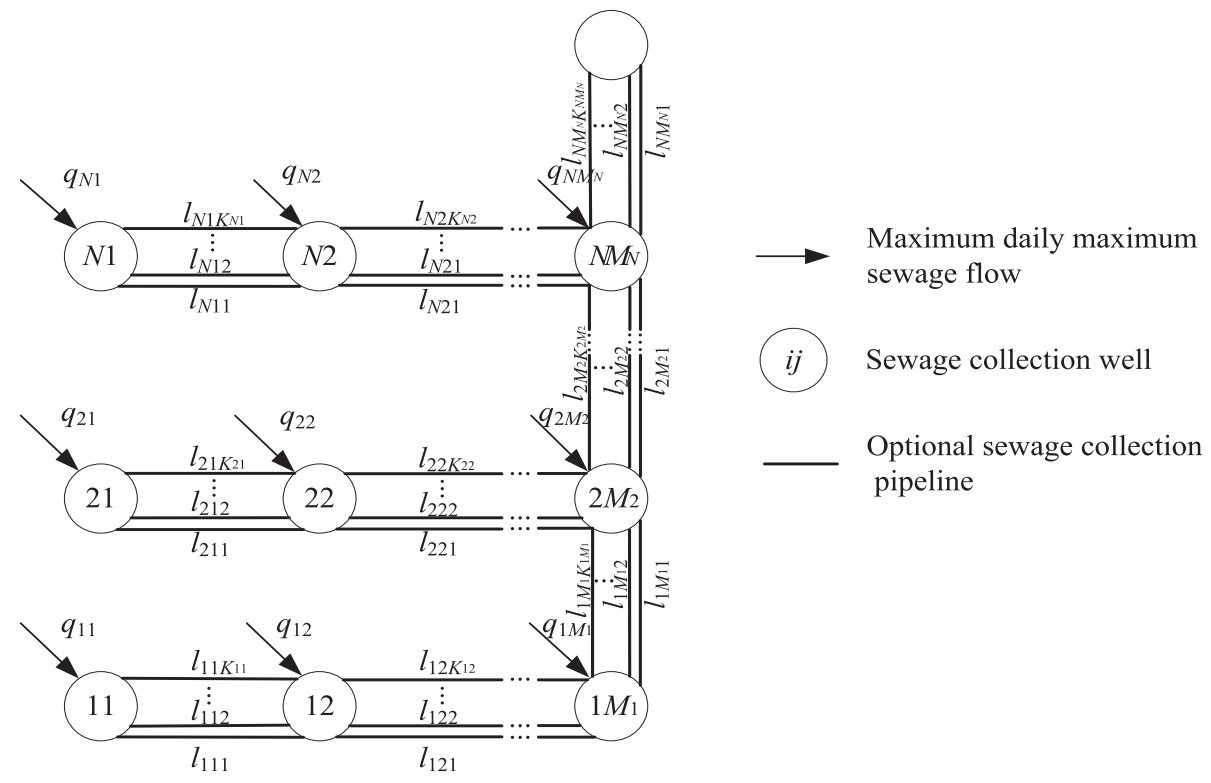

Fig. 1. Generalized diagram of multi-line schemes for urban sewage collection pipe networks. 
cost of the pipe networks for calculation. Thus, the line scheme $k_{i j}$ for pipe section $i j$ and its corresponding pipe diameter $D_{i j k}$ are regarded as decision variables, and the pipe economic life as the calculation analysis period in order to construct the annual cost objective function for the branch and trunk pipes belonging to the $i$-th pipe section of sewage collection pipe networks [9]:

$$
\begin{gathered}
F_{i}=\min \sum_{j=1}^{M_{i}}\left(\alpha_{i j k}+\beta_{i j k}+\theta_{i j k}\right)\left[a_{1}+a_{2} D_{i j k}^{2}+a_{3}\left(h_{i 1 k}^{(1)}\right.\right. \\
\left.\left.-\frac{1}{2} I_{i j k} l_{i j k}+\sum_{p=1}^{j} I_{i p k} l_{i p k}\right)^{2}\right] l_{i j k} \\
I_{i j k}=\left(\frac{2^{13 / 3} \phi_{i j k}^{2 / 3} Q_{i j k} \xi_{i j k}}{D_{i j k}^{8 / 3}\left(\phi_{i j k}-\sin \phi_{i j k}\right)^{5 / 3}}\right)^{2} \\
\phi_{i j k}=4 \arcsin \sqrt{d_{i j k} / D_{i j k}}
\end{gathered}
$$

Equation (1) can be converted into an expression for the decision variable $D_{i j k}$ according to Equations (2) and (3).

In the equations above, $F_{i}$ denotes the minimum annual cost (RMB) of the pipe network for the branch and trunk pipes belonging to the $i$-th pipe section, $D_{i j k} D_{i j k}$ denotes the pipe diameter (m) of pipe section $i j k, I_{i j k}$ denotes the slope of pipe section $i j k, \phi_{i j k}$ denotes the filled angle (radian) of the cross section of pipe section $i j k, d_{i j k} / D_{i j k}$ denotes the fullness of pipe section $i j k$, and $d_{i j k}$ denotes the water depth (m) in the pipeline of pipe section $i j k, \xi_{i j k}$ denotes the pipe wall roughness coefficient for pipe section $i j k, l_{i j k}$ denotes the pipe length (m) for pipe section $i j k, Q_{i j k}$ denotes the maximum daily sewage flow $\left(\mathrm{m}^{3} / \mathrm{s}\right)$ in pipe section $i j k$, $a_{1}, a_{2}$, and $a_{3}$ are constants obtained by fitting with the least squares method, $\alpha_{i j k}$ denotes the equivalent annuity coefficient $\frac{r_{0}\left(1+r_{0}\right)^{t_{j k}}}{\left(1+r_{0}\right)^{t_{j k}}-1}$ for pipe section $i j k, r_{0}$ denotes the social average rate of return $(\%), t_{i j k}$ denotes the economic service life of pipe section $i j k, \beta_{i j k}$ denotes the annual maintenance cost coefficient of pipe section $i j k$, $\theta_{i j k}$ denotes the annual management cost coefficient of pipe section $i j k$, and $h^{(1)}{ }_{i 1 k}$ denotes the burial depth (m) of the pipeline starting point for pipe section $i l k$ without considering variations in the ground elevation.

\section{Constraints on the Branch and Trunk Pipes Belonging to the i-th Pipe Section of Sewage Collection Pipe Networks}

In the sewage collection pipe network, the transportation of sewage relies on gravity, and the pipe diameter and burial depth of the pipe section are greatly affected by the longitudinal slope of the pipe section. During optimization, we mainly consider the key factors such as the head loss at the head and end of sewage collection pipe networks, the longitudinal slope of the pipe section, and the economic flow rate of the pipe section [10].

The coupling constraint is the head loss constraint at the head and end of the branch and trunk pipes belonging to the $i$-th pipe section, as follows.

The head loss constraint for the branch and trunk pipes belonging to the $i$-th pipe section is:

$$
\sum_{j=1}^{M_{i}} I_{i j k} l_{i j k} \leq Z_{i 1 k}^{(1)}-Z_{i M_{i} k}^{(2)}
$$

Equation (4) can also be converted into the expression for the decision variable $D_{i j k}$ according to Equations (2) and (3).

In Equation (4), $I_{i j k}$ denotes the slope of pipe section $i j k, l_{i j k}$ denotes the length (m) of pipe section $i j k$, and $Z^{(1)}{ }_{i 1 k}$ and $Z^{(2)}{ }_{i M_{i} k}$ denote the invert elevations (m) of the pipeline starting point in pipe section $i 1 k$ and the pipeline ending point in pipe section $i M_{i} k$, respectively.

\section{Feasible Region Constraint on the Decision Variable}

Economic rate constraint on the pipe section:

$$
\begin{gathered}
V_{\min } \leq V_{i j k} \leq V_{\max } \\
V_{i j k}=Q_{i j k} / A_{i j k} \\
A_{i j k}=D_{i j k}^{2}\left(\phi_{i j k}-\sin \phi_{i j k}\right) / 8
\end{gathered}
$$

Equation (5) can be converted into the expression for the decision variable $D_{i j k}$ according to Equations (6) and (7).

In the equations above, $V_{i j k}$ denotes the sewage flow rate $(\mathrm{m} / \mathrm{s})$ in pipe section $i j k, V_{\max }$ denotes the maximum allowable pipe sewage flow rate $(\mathrm{m} / \mathrm{s}), V_{\min }$ denotes the minimum allowable pipe sewage flow rate $(\mathrm{m} / \mathrm{s})$, and $A_{i j k}$ denotes the area $\left(\mathrm{m}^{2}\right)$ of the cross section in pipe section ijk. The meanings of other variables are the same as those defined above.

Longitudinal slope constraint on the pipe section:

$$
I_{\min } \leq I_{i j k} \leq I_{\max }
$$

Equation (8) can also be converted into the expression for the decision variable $D_{i j k}$ according to Equations (2) and (3).

In Equation (8), $I_{\max }$ and $I_{\min }$ denote the minimum and maximum allowable pipe slopes with the same diameter, respectively.

Pipe diameter constraint on the pipe section:

$$
D_{\min } \leq D_{i j k} \leq D_{\max }
$$


where $D_{\max }$ and $D_{\min }$ denote the minimum and maximum allowable diameter values in the optional standard pipe diameter set, respectively.

Establishment of a Large System Model for Optimizing the Design of Sewage Collection Pipe Networks

\section{Annual Cost Objective Function for the Whole Sewage Collection Pipe Network}

Based on the annual cost objective function for the branch and trunk pipes in the $i$-th pipe section in the aforementioned sewage collection pipe network, the annual cost objective function of the whole sewage collection pipe network can be constructed as [11]:

$$
F=\min \sum_{i=1}^{M} F_{i}
$$

where $F$ denotes the minimum annual cost (RMB) of the whole sewage collection pipe network.

\section{Constraints on the Whole Sewage Collection Pipe Network}

The head loss in the pipe sections of sewage collection pipe networks is affected by both the pipe burial depth and the head loss constraint at the head and end of the branch and trunk pipes belonging to each pipe section, and it is also restricted by the water level jacking off the main sewage collection pipe [12].

\section{Coupling Constraints}

The head loss constraint at the head and end of the branch and trunk pipes belonging to each pipe section is the same as that given in Equation (4).

The head loss constraint on the trunk pipe section belonging to the whole sewage collection pipe network is:

$$
\sum_{i=1}^{N} I_{i M_{i} k} l_{i M_{i} k} \leq Z_{1 M_{1} k}^{(1)}-Z_{N K_{N} k}^{(2)}
$$

Equation (11) can also be converted into the expression for the decision variable $D_{i j k}$ according to Equations (2) and (3).

In Equation (11), $Z^{(1)}{ }_{1 M_{1} k}, Z^{(2)}{ }_{N M_{N} k}$ denote the invert elevations $(\mathrm{m})$ of the pipeline starting point in pipe section $1 M_{1} k$ and the pipeline ending point in pipe section $N M_{N} k$, respectively. The meanings of the other variables are the same as those defined above.

The feasible region constraints on the decision variables include the flow rate constraint on the pipe section, the longitudinal slope constraint on the pipe section, and the pipe diameter constraint on the pipe section, which are the same as those given in Equations (5)-(9).

Solution Using an Orthogonal Test and Large
System Decomposition-Aggregation Method

Solution Method and Steps [13]

\section{Decomposing the Large System Model into Several Relatively Independent and Interrelated Subsystem Models}

The large system models in Equations (10)-(11) are decomposed into $N$ pipe section optimization design subsystem models. The subsystem model treats the line scheme $k_{i j}$ and pipe diameter $D_{i j k}$ for each division pipe section as decision variables, the water head loss at the head and end of the division pipe section, pipe economic flow rate, pipe longitudinal slope, and optional pipe diameter as constraints, and the minimum annual cost of the branch and trunk pipes belonging to the $i$-th pipe section as the objective function [14].

Objective function:

$$
\begin{gathered}
F_{i}=\min \sum_{j=1}^{M_{i}}\left(\alpha_{i j k}+\beta_{i j k}+\theta_{i j k}\right)\left[a_{1}+a_{2} D_{i j k}^{2}+a_{3}\left(h_{i 1 k}^{(1)}-\right.\right. \\
\left.\left.-\frac{1}{2} I_{i j k} l_{i j k}+\sum_{p=1}^{j} I_{i p k} l_{i p k}\right)^{2}\right] l_{i j k} \\
I_{i j k}=\left(\frac{2^{13 / 3} \phi_{i j k}^{2 / 3} Q_{i j k} \xi_{i j k}}{D_{i j k}^{8 / 3}\left(\phi_{i j k}-\sin \phi_{i j k}\right)^{5 / 3}}\right)^{2} \\
\phi_{i j k}=4 \arcsin \sqrt{d_{i j k} / D_{i j k}}
\end{gathered}
$$

Constraints:

The head loss constraint on the branch and trunk pipes belonging to the $i$-th pipe section is:

$$
\sum_{j=1}^{M_{i}} I_{i j k} l_{i j k} \leq \Delta Z_{i}
$$

The economic rate constraint on the pipe section is:

$$
\begin{gathered}
V_{\min } \leq V_{i j k} \leq V_{\max } \\
V_{i j k}=Q_{i j k} / A_{i j k} \\
A_{i j k}=D_{i j k}^{2}\left(\phi_{i j k}-\sin \phi_{i j k}\right) / 8
\end{gathered}
$$

Longitudinal slope constraint on the pipe section: 


$$
I_{\min } \leq I_{i j k} \leq I_{\max }
$$

Pipe diameter constraint on the pipe section:

$$
D_{\min } \leq D_{i j k} \leq D_{\max }
$$

where $\Delta Z_{i}$ denotes the difference (m) between the invert elevations at the pipeline starting point and the pipeline ending point of the $i$-th pipe section, i.e., $Z^{(1)}{ }_{i 1 k}-Z^{(2)}{ }_{i M_{i} \cdot k}$. The meanings of the other variables are the same as those defined above.

\section{Optimize Each Subsystem Model Separately [15-16]}

Test scheme determination. The division pipe section is treated as the test factor and the optional line scheme for each division pipe section as the test level. The orthogonal table is then selected to determine the test scheme combination for each division pipe section.

Subsystem optimization. Under the condition that the line schemes are known for each division pipe section, Equations (12)-(20) are employed as a one-dimensional dynamic programming model, which treats the number $M_{i}$ of the division pipe section as the stage variable, the pipe diameter $D_{i j k}$ of the division pipe section as the decision variable, and the head loss $\lambda_{s}$ of the division pipe section as the state variable. The state variable $\lambda_{s}$ is discretized in the corresponding feasible region $\Delta Z_{i}$ if the state transition equation is satisfied using the one-dimensional dynamic programming method. The discretization process involves $m$ head loss values $(m=1,2, \ldots, \max )$ and determining the optimal combination value of the diameter for each division pipe section in subsystem $D_{i j k, m}\left(k_{i j, m}\right)(i=1,2, \ldots N$; $\left.j=1,2, \ldots M_{i} ; m=1,2, \ldots, \max \right)$ and the annual cost target value $F_{i, m}\left(k_{i j, m}\right)$.

Orthogonal test-based selection. The range analysis method is used to calculate the annual cost target value $F_{i, m}\left(k_{i j, m}\right)$ corresponding to the test combinations of each division pipe section line scheme, thereby determining the theoretical optimal line scheme combination in the test combination for each division pipe section line scheme $k_{i j}{ }^{*}\left(i=1,2, \ldots N ; j=1,2, \ldots M_{i}\right)$.

For the theoretical combination $k_{i j}{ }^{*}$ of optimal line schemes for each identified division pipe section, the method described in Step (2) is applied to finally obtain the theoretical optimal diameter $D_{i j k, m}$ of each division pipe section and the minimum annual cost target value $F_{i, m}$ of the branch and trunk pipes belonging to the $i$-th pipe section.

After solving the subsystem model, several combinations of annual target cost values $F_{i, m}(m=1,2$, ...,max) and head loss values $\Delta Z_{i, m}(m=1,2, \ldots$, max $)$ can be obtained for the branch and trunk pipes of the $i$-th pipe section of sewage collection pipe networks, as well as the optimal combination $D_{i j k, m}(m=1,2, \ldots, \max )$ of pipe diameters for each division pipe section.
As a result, various relationships comprising $\Delta Z_{i, m}$ $\sim F_{i, m}\left(\Delta Z_{i, m}\right)$ and the corresponding relationships for $\Delta Z_{i M_{i}, k, m} F_{i, m}\left(\Delta Z_{i M_{i} k, m}\right)$ can be obtained.

\section{Dynamic Programming Aggregation of a Large System Model [17]}

The various $\Delta Z_{i M_{i}, k, m} \sim F_{i, m}\left(\Delta Z_{i M_{i}, k, m}\right)$ relationships $(i=1,2, \ldots, N ; m \stackrel{i}{=} 1,2, \ldots, \max )$ obtained from the subsystem models given above are analyzed and fitted to empirical formulae, before substituting into the original large system model given by Equations (10)-(11) to obtain the following large system aggregation model [18].

Objective function:

$$
F=\min \sum_{i=1}^{N} F_{i}\left(\Delta Z_{i M_{i} k}\right)
$$

Constraints:

$$
\sum_{i=1}^{N} \Delta Z_{i M_{i} k} \leq \Delta Z_{t}
$$

where $\Delta Z_{i}$ denotes the difference (m) between the invert elevations at the pipeline starting point and the pipeline ending point of all the trunk pipe sections, i.e., $Z^{(1)}{ }_{1 M_{1} k}-Z^{(2)}{ }_{N M_{1} k^{*}}$.

By solving the above aggregation model with the one-dimensional dynamic programming method, we can obtain the minimum annual cost $F^{*}$ of sewage collection pipe networks that meet the constraints as well as the corresponding head loss $\Delta Z_{i{ }_{i} i k}^{*}$ for each trunk pipe section $(i=1,2, \ldots, N)$. According to the optimal head loss $\Delta Z_{i M_{i k} k}^{*}$ for each trunk pipe section, the optimal head loss $\Delta Z_{i}^{*}$ for the branch and trunk pipes belonging to each trunk pipe section can be calculated. After using $\Delta Z_{i}^{*}$ to assess the optimization results determined for the subsystem models, we can obtain the optimal diameter combination $D^{*}{ }_{i j k}$ $\left(i=1,2, \ldots, N ; j=1,2, \ldots, M_{i}\right)$ for each division pipe section corresponding to the head loss for each pipe section [19]. Flow charts are presented in Figs 2 and 3.

\section{Results and Discussion}

\section{Basic Information about the Calculations}

In the sewage collection pipe network in a specific region of Taizhou, Jiangsu, the pipeline trends and the flow rate at each node in the sewage collection pipe network in this region are illustrated in Fig. 4, where the invert elevation of the sewage collection starting point in each branch pipe section of the pipe network is $3.8 \mathrm{~m}$ (Yellow Sea Elevation System), the invert elevation of the sewage collection ending 


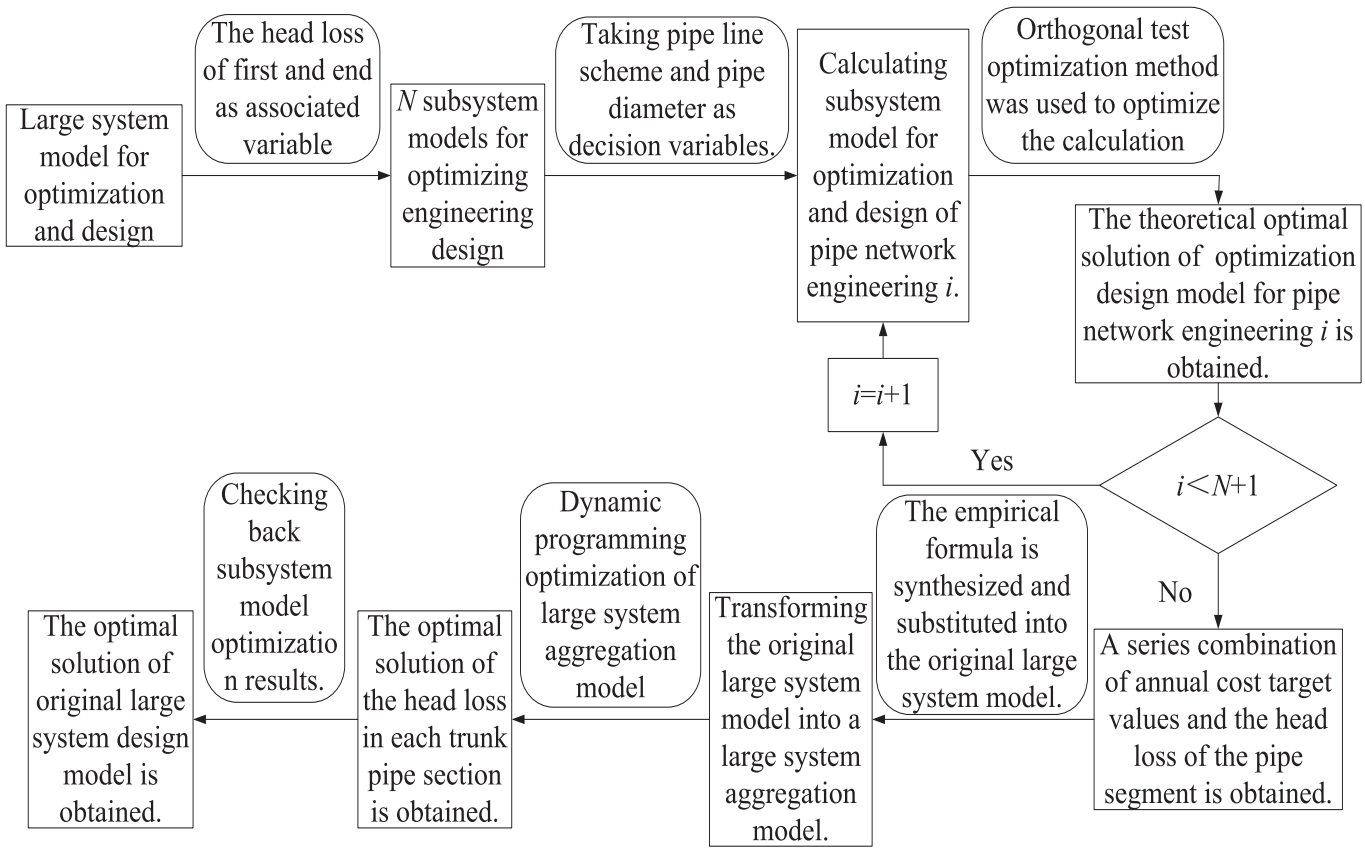

Fig. 2. Process followed for calculating the large system model.

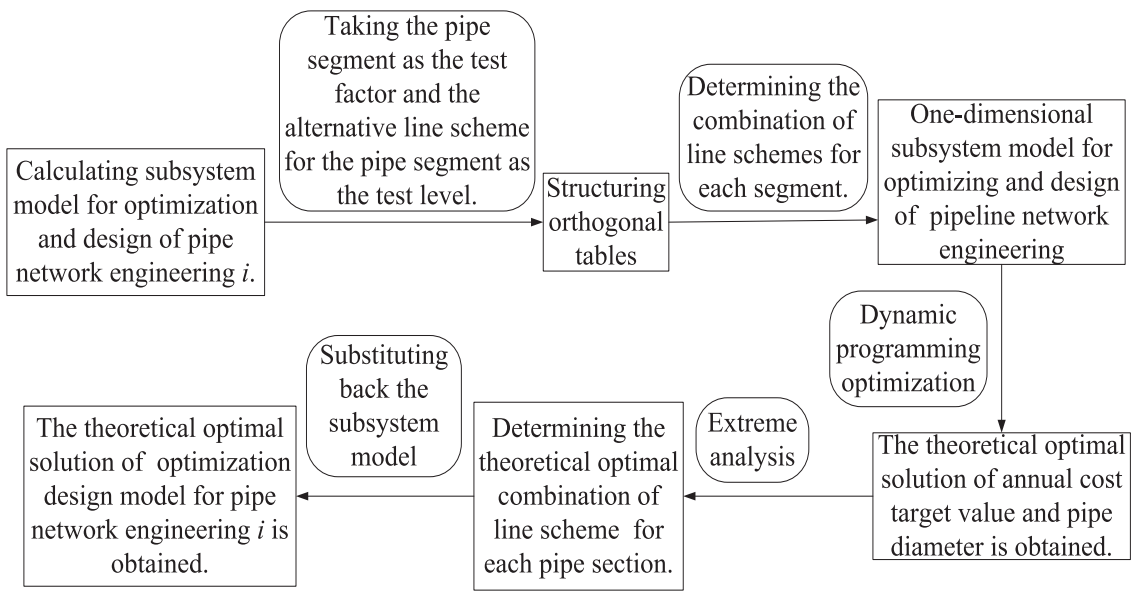

Fig. 3. Process followed for calculating the subsystem model for the $i$-th pipe section.

point in the trunk pipe section of the pipe network is $2.2 \mathrm{~m}$, and the flat ground elevation is $4.8 \mathrm{~m}$. In addition, the line scheme and pipe length for each division pipe section are illustrated in Table 1 . The construction method involved applying mediumfine sand backfilling and compacting around the GRP (Glass Reinforced Plastic) sand pipe and HDPE (High Density Polyethylene) pipe. The reinforced concrete pipe base has sandstone or concrete foundations. In this study, the social average rate of return $r_{0}$ was treated as $10 \%$. The economic service life $t$ is 20 years for reinforced concrete pipes, 30 years for HDPE pipes, and 30 years for GRP sand pipes. The annual maintenance cost coefficient of the pipe section is $2 \%$ and the annual management cost coefficient of the pipe section is $1 \%$. The construction cost indices corresponding to the specifications of the local GRP sand pipe, HDPE pipe, and reinforced concrete pipe are shown in Tables 2, 3, and 4, respectively. The pipe economic flow rate is between $0.6 \mathrm{~m} / \mathrm{s}$ and $2.5 \mathrm{~m} / \mathrm{s}$.

\section{Solution Processes and Optimization Results}

\section{Calculation of the Optional Standard Pipe Diameter for each Division Pipe Section According to the Economic Flow Rate Constraint on the Pipe Section}

Using Equations (5)-(7), the pipe diameter range for each division pipe section was calculated with a pipe economic flow rate of $0.6-2.5 \mathrm{~m} / \mathrm{s}$ in order to derive the optional standard pipe diameter set for each division pipe section, as shown in Table 5. 


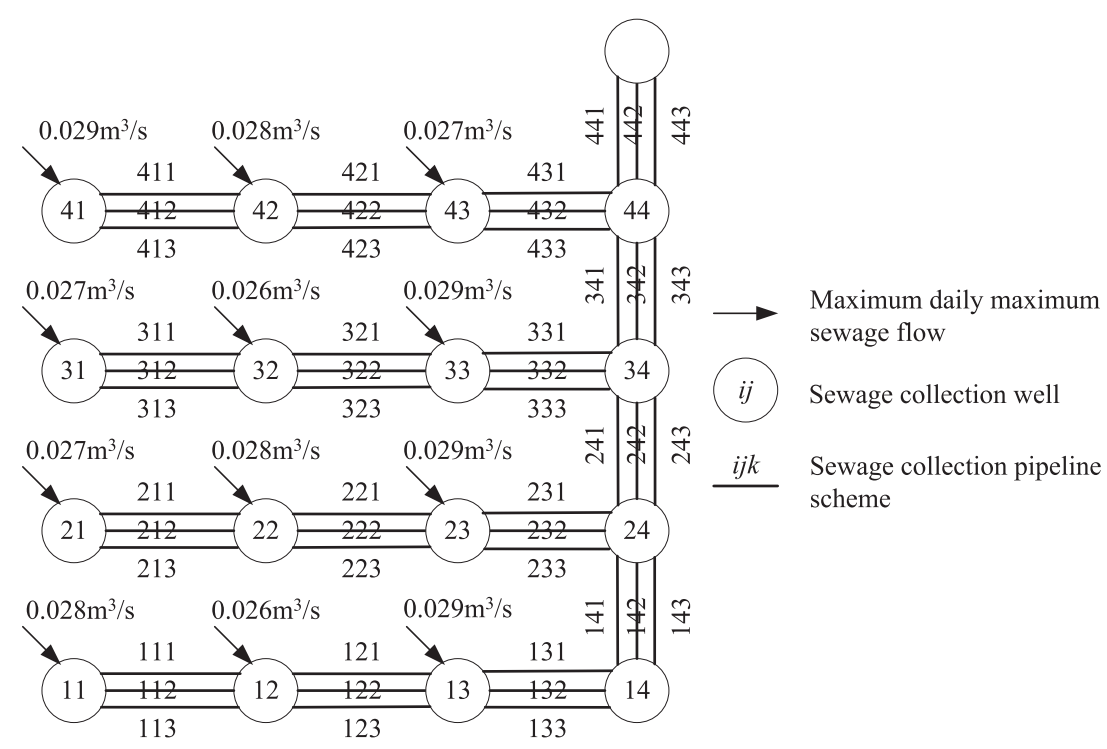

Fig. 4. Generalized diagram showing the multi-line schemes for sewage collection pipe networks in a certain area.

Table 1. Line schemes for division pipe sections and the corresponding pipeline lengths.

\begin{tabular}{|c|c|c|c|c|c|}
\hline $\begin{array}{l}\text { Pipe section } \\
\text { number }\end{array}$ & $\begin{array}{l}\text { Pipe section } \\
\text { name }\end{array}$ & $\begin{array}{l}\text { Division pipe } \\
\text { section number }\end{array}$ & $\begin{array}{c}\text { Line scheme } \\
\text { name }\end{array}$ & Division pipe section line scheme & Length $/ \mathrm{m}$ \\
\hline \multirow{12}{*}{1} & \multirow{12}{*}{$\begin{array}{c}\text { Node } 11 \text {-Node } \\
24\end{array}$} & \multirow{3}{*}{11} & 111 & H-pipe & 110 \\
\hline & & & 112 & G-pipe & 112 \\
\hline & & & 113 & R-pipe & 122 \\
\hline & & \multirow{3}{*}{12} & 121 & H-pipe & 120 \\
\hline & & & 122 & G-pipe & 121 \\
\hline & & & 123 & R-pipe & 131 \\
\hline & & \multirow{3}{*}{13} & 131 & H-pipe & 110 \\
\hline & & & 132 & G-pipe & 112 \\
\hline & & & 133 & R-pipe & 121 \\
\hline & & \multirow{3}{*}{14} & 141 & H-pipe & 120 \\
\hline & & & 142 & G-pipe & 122 \\
\hline & & & 143 & R-pipe & 133 \\
\hline \multirow{12}{*}{2} & \multirow{12}{*}{$\begin{array}{c}\text { Node } 21 \text {-Node } \\
34\end{array}$} & \multirow{3}{*}{21} & 211 & H-pipe & 115 \\
\hline & & & 212 & G-pipe & 117 \\
\hline & & & 213 & R-pipe & 125 \\
\hline & & \multirow{3}{*}{22} & 221 & H-pipe & 115 \\
\hline & & & 222 & G-pipe & 116 \\
\hline & & & 223 & R-pipe & 124 \\
\hline & & \multirow{3}{*}{23} & 231 & H-pipe & 111 \\
\hline & & & 232 & G-pipe & 113 \\
\hline & & & 233 & R-pipe & 121 \\
\hline & & \multirow{3}{*}{24} & 241 & H-pipe & 118 \\
\hline & & & 242 & G-pipe & 119 \\
\hline & & & 243 & R-pipe & 129 \\
\hline
\end{tabular}


Table 1. Continued.

\begin{tabular}{|c|c|c|c|c|c|}
\hline \multirow{12}{*}{3} & \multirow{12}{*}{$\begin{array}{c}\text { Node } 31 \text {-Node } \\
44\end{array}$} & \multirow{3}{*}{31} & 311 & H-pipe & 105 \\
\hline & & & 312 & G-pipe & 107 \\
\hline & & & 313 & R-pipe & 116 \\
\hline & & \multirow{3}{*}{32} & 321 & H-pipe & 115 \\
\hline & & & 322 & G-pipe & 117 \\
\hline & & & 323 & R-pipe & 126 \\
\hline & & \multirow{3}{*}{33} & 331 & H-pipe & 120 \\
\hline & & & 332 & G-pipe & 121 \\
\hline & & & 333 & R-pipe & 129 \\
\hline & & \multirow{3}{*}{34} & 341 & H-pipe & 116 \\
\hline & & & 342 & G-pipe & 118 \\
\hline & & & 343 & R-pipe & 128 \\
\hline \multirow{12}{*}{4} & \multirow{12}{*}{$\begin{array}{c}\text { Node } \\
\text { 41-Destination }\end{array}$} & \multirow{3}{*}{41} & 411 & H-pipe & 115 \\
\hline & & & 412 & G-pipe & 115 \\
\hline & & & 413 & R-pipe & 127 \\
\hline & & \multirow{3}{*}{42} & 421 & H-pipe & 112 \\
\hline & & & 422 & G-pipe & 113 \\
\hline & & & 423 & R-pipe & 122 \\
\hline & & \multirow{3}{*}{43} & 431 & H-pipe & 118 \\
\hline & & & 432 & G-pipe & 120 \\
\hline & & & 433 & R-pipe & 127 \\
\hline & & \multirow{3}{*}{44} & 441 & H-pipe & 120 \\
\hline & & & 442 & G-pipe & 121 \\
\hline & & & 443 & R-pipe & 133 \\
\hline
\end{tabular}

Note: H-pipe - HDPE pipe; G-pipe - GRP sand pipe; R-pipe - Reinforced concrete pipe

Table 2. Construction cost indices for the HDPE pipe.

\begin{tabular}{|c|c|c|c|c|c|c|c|c|c|c|}
\hline Pipe specification number & 1 & 2 & 3 & 4 & 5 & 6 & 7 & 8 & 9 & 10 \\
\hline Pipe diameter $/ \mathrm{m}$ & 0.225 & 0.25 & 0.3 & 0.4 & 0.5 & 0.6 & 0.7 & 0.8 & 0.9 & 1.0 \\
\hline Thickness of upper protective layer $/ \mathrm{m}$ & 0.75 & 0.75 & 0.75 & 0.75 & 0.75 & 0.75 & 0.75 & 0.75 & 0.75 & 0.75 \\
\hline Construction cost per meter $/ \mathrm{RMB} \mathrm{m}^{-1}$ & 197.74 & 220.74 & 272.93 & 402.07 & 564.24 & 759.42 & 987.63 & 1248.85 & 1543.09 & 1870.35 \\
\hline
\end{tabular}

Table 3. Construction cost indices for the GRP sand pipe.

\begin{tabular}{|c|c|c|c|c|c|c|c|c|c|c|}
\hline Pipe specification number & 1 & 2 & 3 & 4 & 5 & 6 & 7 & 8 & 9 & 10 \\
\hline Pipe diameter $/ \mathrm{m}$ & 0.225 & 0.25 & 0.3 & 0.4 & 0.5 & 0.6 & 0.7 & 0.8 & 0.9 & 1.0 \\
\hline Thickness of upper protective layer $/ \mathrm{m}$ & 0.75 & 0.75 & 0.75 & 0.75 & 0.75 & 0.75 & 0.75 & 0.75 & 0.75 & 0.75 \\
\hline Construction cost per meter $/ \mathrm{RMB} \mathrm{m}^{-1}$ & 209.93 & 232.6 & 283.92 & 410.53 & 569.07 & 759.56 & 981.99 & 1236.36 & 1522.67 & 1840.93 \\
\hline
\end{tabular}


Table 4. Construction cost indices for the reinforced concrete pipe.

\begin{tabular}{|c|c|c|c|c|c|c|c|c|c|c|}
\hline Pipe specification number & 1 & 2 & 3 & 4 & 5 & 6 & 7 & 8 & 9 & 10 \\
\hline Pipe diameter $/ \mathrm{m}$ & 0.225 & 0.25 & 0.3 & 0.4 & 0.5 & 0.6 & 0.7 & 0.8 & 0.9 & 1.0 \\
\hline Thickness of upper protective layer $/ \mathrm{m}$ & 0.75 & 0.75 & 0.75 & 0.75 & 0.75 & 0.75 & 0.75 & 0.75 & 0.75 & 0.75 \\
\hline Construction cost per meter $/ \mathrm{RMB} \mathrm{m}^{-1}$ & 193.52 & 213.87 & 259.9 & 373.15 & 514.73 & 684.63 & 882.85 & 1109.4 & 1364.24 & 1647.4 \\
\hline
\end{tabular}

Table 5. Optional standard pipe diameters for the division pipe sections and the optimized sizes.

\begin{tabular}{|c|c|c|c|c|c|c|c|c|c|c|c|c|}
\hline $\begin{array}{l}\text { Pipe section } \\
\text { name }\end{array}$ & Division pipe & \multicolumn{9}{|c|}{ Optional standard pipe diameter /m } & \multirow{2}{*}{$\begin{array}{c}\begin{array}{c}\text { Division pipe } \\
\text { section line scheme }\end{array} \\
111\end{array}$} & \multirow{2}{*}{$\frac{\begin{array}{c}\text { Optimized } \\
\text { diameter } / \mathrm{m}\end{array}}{0.3}$} \\
\hline \multirow{4}{*}{$\begin{array}{c}\text { Node } 11 \text {-Node } \\
24\end{array}$} & 11 & 0.225 & 0.25 & 0.3 & - & - & - & - & - & - & & \\
\hline & 12 & 0.225 & 0.25 & 0.3 & 0.4 & - & - & - & - & - & 121 & 0.4 \\
\hline & 13 & - & 0.25 & 0.3 & 0.4 & 0.5 & - & - & - & - & 131 & 0.4 \\
\hline & 14 & - & 0.25 & 0.3 & 0.4 & 0.5 & - & - & - & - & 143 & 0.5 \\
\hline \multirow{4}{*}{$\begin{array}{c}\text { Node } 21 \text {-Node } \\
34\end{array}$} & 21 & 0.225 & 0.25 & 0.3 & - & - & - & - & - & - & 211 & 0.25 \\
\hline & 22 & 0.225 & 0.25 & 0.3 & 0.4 & - & - & - & - & - & 221 & 0.3 \\
\hline & 23 & - & 0.25 & 0.3 & 0.4 & 0.5 & - & - & - & - & 231 & 0.4 \\
\hline & 24 & - & - & - & 0.4 & 0.5 & 0.6 & 0.7 & - & - & 243 & 0.6 \\
\hline \multirow{4}{*}{$\begin{array}{c}\text { Node } 31 \text {-Node } \\
44\end{array}$} & 31 & 0.225 & 0.25 & 0.3 & - & - & - & - & - & - & 311 & 0.225 \\
\hline & 32 & 0.225 & 0.25 & 0.3 & 0.4 & - & - & - & - & - & 321 & 0.25 \\
\hline & 33 & - & 0.25 & 0.3 & 0.4 & 0.5 & - & - & - & - & 331 & 0.3 \\
\hline & 34 & - & - & - & 0.4 & 0.5 & 0.6 & 0.7 & 0.8 & - & 343 & 0.6 \\
\hline \multirow{4}{*}{$\begin{array}{l}\text { Node } \\
\text { 41-Destination }\end{array}$} & 41 & 0.225 & 0.25 & 0.3 & - & - & - & - & - & - & 411 & 0.225 \\
\hline & 42 & 0.225 & 0.25 & 0.3 & 0.4 & - & - & - & - & - & 421 & 0.25 \\
\hline & 43 & - & 0.25 & 0.3 & 0.4 & 0.5 & - & - & - & - & 431 & 0.3 \\
\hline & 44 & - & - & - & - & 0.5 & 0.6 & 0.7 & 0.8 & 0.9 & 443 & 0.7 \\
\hline
\end{tabular}

Note: „—” indicates that no pipe was used.

Fitting the Investment Calculation Equation for Pipe Laying According to the Construction Cost Indices of the Known Pipes

Using the data in Tables 2, 3, and 4, the investment calculation equation for pipe laying was fitted with the least squares method to determine the coefficients $a_{1}$, $a_{2}$, and $a_{3}$ for the calculation equation.

The relationship between the investment amount per unit length of the fitted HDPE pipe, the pipe diameter, and the pipe burial depth is:

$$
c_{g 1}=32.68+1560.42 D_{i j 1}^{2}+90.53 h_{i j 1}^{2} .
$$

The relationship between the investment amount per unit length of the GRP sand pipe, the pipe diameter, and the pipe burial depth is:

$$
c_{g 2}=40.23+1498.37 D_{i j 2}^{2}+98.72 h_{i j 2}^{2}
$$

The relationship between the investment amount per unit length of the reinforced concrete pipe, the pipe diameter, and the pipe burial depth is:

$$
c_{g 3}=26.32+1337.27 D_{i j 3}^{2}+78.62 h_{i j 3}^{2}
$$

where $c_{g 1}, c_{g 2}$, and $c_{g 3}$ denote the construction cost $(\mathrm{RMB} / \mathrm{m})$ per unit length for the HDPE pipe, GRP sand pipe, and reinforced concrete pipe, respectively; $D_{i j 1}, D_{i j 2}$, and $D_{i j 3}$ denote the diameter (m) of division pipe section $i j$ in line scheme 1, line scheme 2, and line scheme 3 ; and $h_{i j 1}, h_{i j 2}$, and $h_{i j 3}$ denote the average burial depth (m) of division pipe section $i j$ in line scheme 1 , line scheme 2 , and line scheme 3 . The meanings of the other variables are the same as those defined above. 


\section{Optimization Calculation for Sewage Collection Pipe Networks}

The relevant parameters were substituted into Models (1)-(11) and the model obtained was optimized with the orthogonal test and large system decomposition-aggregation methods.

First, we decomposed the large system model into four pipe section optimization design subsystem models. Each subsystem model was a mathematical model for optimizing the design of the sewage collection branch and trunk pipes, where we treated the line scheme $k_{i j}$ and pipe diameter $D_{i j k}$ of each division pipe section as decision variables, the head loss at the head and end of the division pipe section, pipe economic flow rate, pipe longitudinal slope, and optional pipe diameter as coupling constraints, and the minimum annual cost of the branch and trunk pipes belonging to the $i$-th pipe section as the objective function.

We then optimized each subsystem model separately.

The division pipe section was treated as the test factor and the pipe network had four test factors. According to the actual situation for the pipe network, the line scheme of each division pipe section was set at three levels. Thus, an orthogonal table was selected containing four factors and three levels, i.e., an $L_{9}$ $\left(3^{4}\right)$-type orthogonal table, where the total number of combination was $3^{4}$. The theoretical optimal solutions in the 81 schemes corresponding to all combinations were obtained according to the nine test schemes selected by the orthogonal table. Due to space limitations, only the relevant data for the branch and trunk pipes in the first pipe section are listed for the test combinations and corresponding target values in Table 6 .

\section{Dynamic Programming Optimization of the Subsystem}

The test level combination of nine division pipe section line schemes determined by the orthogonal table was sequentially substituted into the subsystem models given in Equations (12)-(20). Next, after solving the one-dimensional dynamic programming model, we obtained the optimum pipe diameter $D_{i j}\left(k_{i j}\right)$ under the combinations of the line schemes for each division pipe section and the total annual cost target value $F\left(k_{i j}\right)$ for the corresponding sewage collection pipe network, as shown in Table 6.

\section{Range Analysis to Determine the Theoretical Optimal Line Scheme Combination}

The test level combinations of nine division pipe section line schemes in the $L_{9}\left(3^{4}\right)$-type orthogonal table were analyzed under single factor conditions and different levels. The average values for the test indices comprising $k_{1}, k_{2}$, and $k_{3}$ as well as the range $R$ of each factor corresponding to the test level are shown in Table 7. By comparing the $k$ values at different test levels for each test factor, where the level of a small $k$ value was taken as the optimal level, the theoretical optimal test scheme was obtained. The optimal combination $k_{1 j}^{*}$ for the line scheme in each division pipe section among all combinations $\left(3^{4}=81\right)$ was obtained by range analysis, i.e., $k_{11}^{*}=1$, $k^{*}{ }_{12}=1, k_{13}^{*}=1$, and $k_{14}^{*}=3$.

Solutions of the Combinations for the Annual Cost Target Value and Head Loss in the Subsystem Model

After substituting the optimal combination $k_{1 j}^{*}$ for each division pipe section line scheme into models (12)-(20), we obtained the theoretical optimal diameter $D^{*}{ }_{1 j k, m}$ of each division pipe section and the minimum annual target value $F_{1, m}$ of the branch and trunk pipes belonging to the first pipe section.

By solving the subsystem model, we obtained the optimal combination $k_{i j}^{*}(i=1,2,3,4 ; j=1,2,3,4)$ of the division pipe section line scheme for the whole

Table 6. Orthogonal table of test combinations for line schemes in division pipe sections and the corresponding target cost.

\begin{tabular}{|c|c|c|c|c|c|}
\hline \multirow{2}{*}{ Test scheme } & \multicolumn{4}{|c|}{ Test level for line scheme in division pipe section } & \multirow{2}{*}{ Target cost /RMB } \\
\hline & 1 & 2 & 3 & 4 & \\
\hline 1 & 1 & 1 & 1 & 1 & 33139.03 \\
\hline 2 & 1 & 2 & 2 & 2 & 35265.41 \\
\hline 3 & 1 & 3 & 3 & 3 & 34173.22 \\
\hline 4 & 2 & 1 & 2 & 3 & 34986.34 \\
\hline 5 & 2 & 2 & 3 & 1 & 36817.96 \\
\hline 6 & 2 & 3 & 1 & 2 & 35164.35 \\
\hline 7 & 3 & 1 & 3 & 2 & 35016.23 \\
\hline 8 & 3 & 2 & 1 & 3 & 33721.36 \\
\hline 9 & 3 & 3 & 2 & 1 & 36928.49 \\
\hline
\end{tabular}


Table 7. Range analysis table.

\begin{tabular}{|c|c|c|c|c|}
\hline \multirow{2}{*}{ Test scheme } & \multicolumn{3}{|c|}{ Corresponding mean values of the index values for each factor under different test levels (RMB) } \\
\cline { 2 - 5 } & 1 & 2 & 3 & 4 \\
\hline$k_{1}^{a}$ & $34192.55^{*}$ & $34380.53^{*}$ & $34008.25^{*}$ & 35628.49 \\
\hline$k_{2}$ & 35656.22 & 35268.24 & 35726.75 & 35148.66 \\
\hline$k_{3}$ & 35222.03 & 35422.02 & 35335.80 & $34293.64^{*}$ \\
\hline$R^{b}$ & 1463.67 & 1041.49 & 1718.50 & 1334.85 \\
\hline
\end{tabular}

${ }^{a} k_{1}, k_{2}$, and $k_{3}$ are the corresponding mean index values for each factor under different test levels.

${ }^{b} \mathrm{R}$ is the variation range for the test index of the factor over its range of values.

*Optimal level combination.

sewage collection pipe network, as shown in Table 5, the combinations of the annual cost target values $F_{i, m}$ $(i=1,2,3,4 ; m=1,2, \ldots, 18)$ and head loss $\Delta Z_{i, m}(i=1$, $2,3,4 ; m=1,2, \ldots, 18)$ for the series of branch and trunk pipes belonging to each pipe section, and the optimal pipe diameter combination $D_{i j k, m}(i=1,2,3,4 ; j=1$, $2,3,4 ; m=1,2, \ldots, 18)$ for each division pipe section. Thus, we obtained various $\Delta Z_{i, m} \sim F_{i, m}\left(\Delta Z_{i, m}\right)$ relationships and the corresponding $\Delta Z_{i M_{i} k, m} \sim F_{i, m}\left(\Delta Z_{i M_{i} k, m}\right)$ relationships.

Next, the $\Delta Z_{i M, k, m} \sim F_{i, m}\left(\Delta Z_{i M_{i}, m}\right)$ relationships $(i=1$, $2,3,4 ; m=1,2, \ldots, 18)$ obtained from the four subsystem models were fitted to the empirical formula and substituted into the large system aggregation models given by Equations (21)-(22).

The one-dimensional dynamic programming method was used to solve the aggregation model and we then determined the minimum annual cost of the sewage collection pipe network $F^{*}$ as 151,037 $\mathrm{RMB}$, which satisfied the constraint conditions, and the corresponding head loss $\Delta Z_{i M_{i k} k}^{*}(i=1,2,3,4)$ for each trunk pipe section. According to the optimal head loss $\Delta Z_{i M_{i} k}^{*}$ for each trunk pipe section, we calculated the optimal head loss $\Delta Z_{i}^{*}$ for each branch and trunk pipe belonging to the trunk pipe section. After using $\Delta Z^{*}$ to assess the optimization results for the subsystem models, we obtained the optimal pipe diameter combination $D_{i j k}^{*}(i=1,2,3,4 ; j=1,2,3,4 ; k=1,2,3)$ for each division pipe section corresponding to the head loss for each pipe section, as shown in Table 5. The invert elevation trend for each division pipe section in the sewage collection pipe network is shown in Fig. 5.

The traditional optimization method involved selecting the shortest distance line scheme 1 for the whole sewage collection pipe network. HDPE pipes were used for laying and the branch and trunk pipe sections were optimized along the direction of the sewage collection flow. The selection of the line scheme and the rational distribution of the total head loss between the secondary pipe sections of the sewage collection branch and trunk pipes were not considered in a comprehensive manner. The optimization results determined a total annual cost of $F=159820$ RMB and the optimal pipe diameter combination $D_{i j}$ for each division pipe section, as shown in Table 8. The invert

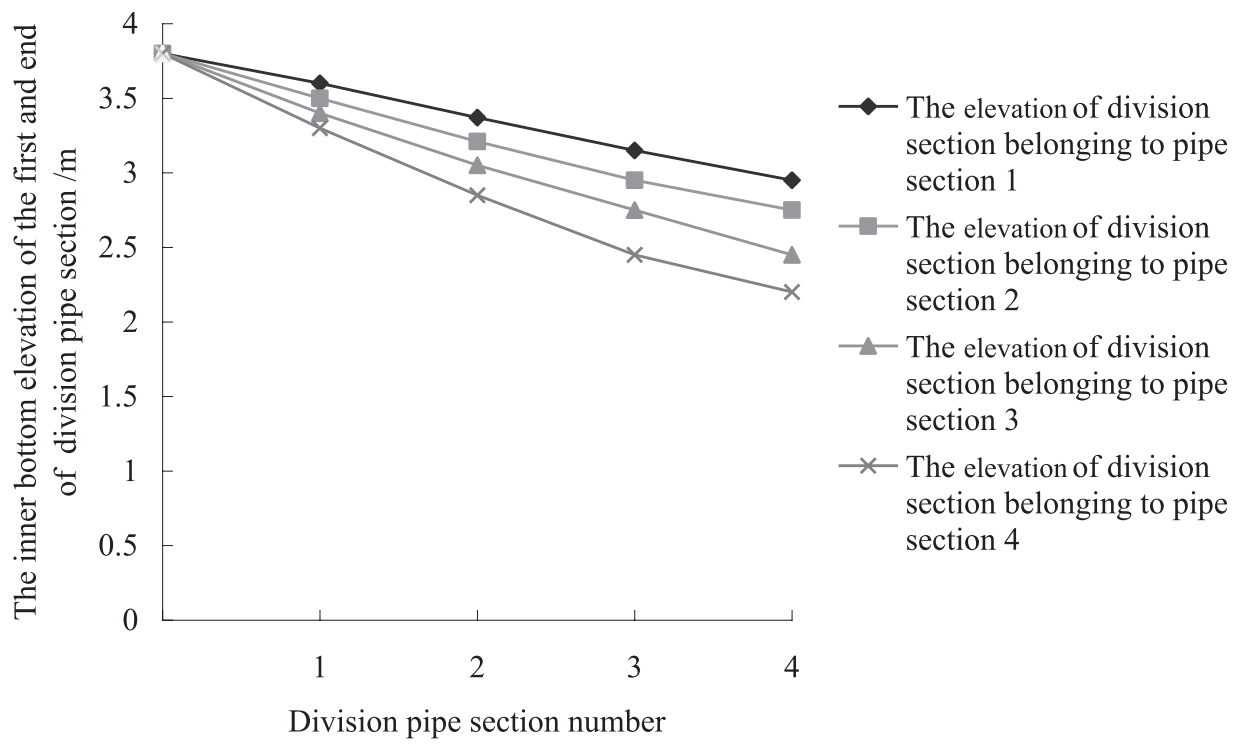

Fig. 5. Trends in inner bottom elevation for division pipe sections in the sewage collection pipe network. 
Table 8. Optional standard pipe diameters in the division pipe section and optimized size obtained using the traditional method.

\begin{tabular}{|c|c|c|c|c|c|c|c|c|c|c|c|c|}
\hline \multirow{2}{*}{$\begin{array}{c}\text { Pipe section } \\
\text { name }\end{array}$} & \multirow{2}{*}{$\begin{array}{c}\begin{array}{c}\text { Division pipe } \\
\text { section number }\end{array} \\
11\end{array}$} & \multicolumn{9}{|c|}{ Optional standard pipe diameter $/ \mathrm{m}$} & \multirow{2}{*}{$\begin{array}{c}\begin{array}{c}\text { Division pipe } \\
\text { section line } \\
\text { scheme }\end{array} \\
111\end{array}$} & \multirow{2}{*}{$\begin{array}{c}\begin{array}{c}\text { Optimized } \\
\text { diameter } / \mathrm{m}\end{array} \\
0.25\end{array}$} \\
\hline & & 0.225 & 0.25 & 0.3 & - & - & - & - & - & - & & \\
\hline \multirow{3}{*}{$\begin{array}{c}\text { Node } 11 \text {-Node } \\
24\end{array}$} & 12 & 0.225 & 0.25 & 0.3 & 0.4 & - & - & 一 & - & - & 121 & 0.3 \\
\hline & 13 & - & 0.25 & 0.3 & 0.4 & 0.5 & - & - & - & - & 131 & 0.4 \\
\hline & 14 & - & 0.25 & 0.3 & 0.4 & 0.5 & - & 一 & - & - & 141 & 0.5 \\
\hline \multirow{4}{*}{$\begin{array}{c}\text { Node } 21 \text {-Node } \\
34\end{array}$} & 21 & 0.225 & 0.25 & 0.3 & - & - & - & - & - & - & 211 & 0.25 \\
\hline & 22 & 0.225 & 0.25 & 0.3 & 0.4 & - & - & - & - & - & 221 & 0.3 \\
\hline & 23 & - & 0.25 & 0.3 & 0.4 & 0.5 & - & - & - & - & 231 & 0.4 \\
\hline & 24 & - & - & - & 0.4 & 0.5 & 0.6 & 0.7 & - & - & 241 & 0.6 \\
\hline \multirow{4}{*}{$\begin{array}{c}\text { Node } 31 \text {-Node } \\
44\end{array}$} & 31 & 0.225 & 0.25 & 0.3 & - & - & - & - & - & - & 311 & 0.25 \\
\hline & 32 & 0.225 & 0.25 & 0.3 & 0.4 & - & - & - & - & - & 321 & 0.3 \\
\hline & 33 & - & 0.25 & 0.3 & 0.4 & 0.5 & - & - & - & - & 331 & 0.4 \\
\hline & 34 & - & - & - & 0.4 & 0.5 & 0.6 & 0.7 & 0.8 & - & 341 & 0.7 \\
\hline \multirow{4}{*}{$\begin{array}{c}\text { Node } \\
\text { 41-Destination }\end{array}$} & 41 & 0.225 & 0.25 & 0.3 & - & - & - & - & - & - & 411 & 0.25 \\
\hline & 42 & 0.225 & 0.25 & 0.3 & 0.4 & - & - & - & - & - & 421 & 0.3 \\
\hline & 43 & - & 0.25 & 0.3 & 0.4 & 0.5 & - & - & - & - & 431 & 0.4 \\
\hline & 44 & - & - & - & - & 0.5 & 0.6 & 0.7 & 0.8 & 0.9 & 441 & 0.8 \\
\hline
\end{tabular}

Note: ,_-" indicates that no pipe was used.

elevation trend for each division pipe section in the sewage collection pipe network is shown in Fig. 6.

\section{Discussion of Optimization Results}

We proposed orthogonal test and large system decomposition-aggregation methods to solve a mathema- tical model for optimizing the design of sewage collection pipe networks. This approach resolves the optimization problem for the line scheme in each division pipe section, as well as integrating the global optimization of the allowable head loss in the secondary pipe network. By contrast, the traditional optimization method tends to optimize the branch pipe section

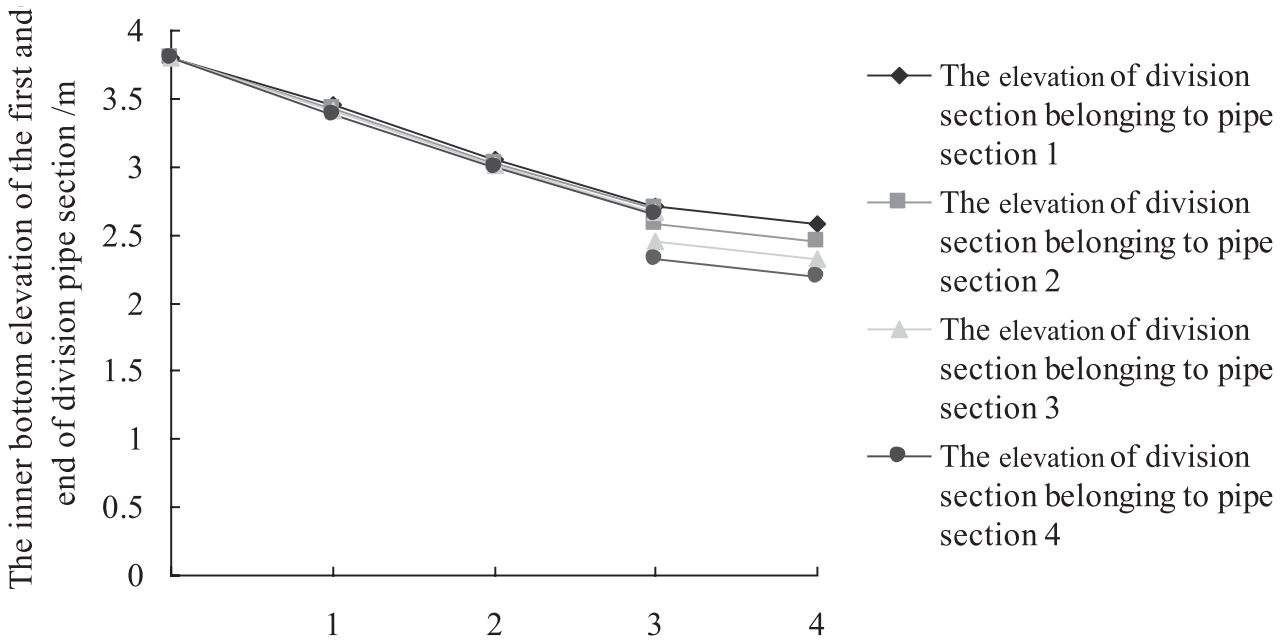

Division pipe section number

Fig. 6. Trends in inner bottom elevation of division pipe sections in the sewage collection pipe network determined using the traditional method. 
and the trunk pipe section. Compared with the optimization results produced using the traditional optimization method, we found that the annual cost target value obtained by the proposed optimization method was $5.5 \%$ lower.

As shown in Tables 6 and 7, the proposed orthogonal test-based selection method obtained the theoretical optimum solutions for 81 test scheme combinations of the corresponding subsystems and 324 test schemes for large systems by selecting nine test scheme combinations for the division pipe section line scheme in each subsystem, and 36 test scheme combinations for the division pipe section line scheme in large systems. This approach greatly reduced the workload incurred for optimization design and calculating the whole sewage collection pipe network, as well as improving the computational running speed and ensuring the accuracy of the optimized design.

Tables 5 and 8 show that the proposed method for globally optimizing the distribution of the allowable head loss in the secondary pipe network yielded the pipe diameter optimization results for each division pipe section. In particular, the upper limit of the optional standard pipe diameter range for the pipe section was considered in the initial stage for the pipe network, and the middle and lower limits of the optional standard pipe diameter range of the pipe section were considered in the middle and late stages for the pipe network. By contrast, the traditional optimization method does not consider the globally optimized distribution of the allowable head loss in the secondary pipe network. By satisfying the constraints on the ending point burial depth for the sewage collection pipe network, we selected the diameter of the pipe section with the lowest unit cost for pipeline laying in order to reduce the annual cost of the pipe network.

Figs 5 and 6 show that the invert elevation trend determined for each division pipe section in the sewage collection pipe network was relatively flat and continuous using the proposed optimization method. The cumulative slope for each division pipe section belonging to the first pipe section was $0.85 \mathrm{~m}$. By contrast, the invert elevation trend for each division pipe section in the sewage collection network was relatively steep and discontinuous when optimized using the traditional optimization method. The cumulative slope of each division pipe section belonging to the first pipe section was $1.22 \mathrm{~m}$. This difference was obtained because the traditional optimization method optimizes the branch pipe section and the trunk pipe section separately, and it fails to consider the influence of the diameter selected for the branch pipe section on the diameter of the trunk pipe section.

\section{Conclusions}

In this study, a new method based on orthogonal test and large system decomposition-aggregation methods can obtain the optimum selection for each division pipe line scheme and determine the optimum pipe diameter for each division pipe section in the pipe network.

By integrating the optimization of the line scheme for each division pipe section and the coupling constraints on the head loss at the head and end of the whole sewage collection pipe network, the diameter of each division pipe section can be optimized to minimize the total annual cost of the whole sewage collection pipe network, thereby resulting in economic benefits from a global optimization perspective, that is, the annual cost target value is $5.5 \%$ lower than the traditional optimization method.

The proposed method based on an orthogonal test and large system decomposition-aggregation can combine various large system optimization methods as well as contributing to large system optimization theory, thereby allowing the theory to be applied to various engineering practices.

The proposed large system optimization method is of theoretical significance to delve into the method of optimizing the design of urban rainwater drainage pipe networks.

\section{Acknowledgments}

We would like to thank the financial support from National Science and Technology Support: 2015BAB07B01, Pumping Station Optimal Operation of the Eastern Route of South-to-North Water Transfer.

\section{Conflict of Interest}

The Authors declare no conflict of interest.

\section{References}

1. ALI H., Amin E.B. Deterministic integrated optimization model for sewage collection networks using tabu search. J Water Res Plan Manag, 04014045 (1-11), 2014.

2. KAROVIC O., MAYS L.W. Sewer System Design Using Simulated Annealing in Excel Water. Resour Manag, 28 (4551-4565), 2014.

3. ZHAO B., HOU D., CHEN H., WANG Y., QIU J. Optimization design of a double-channel pump by means of orthogonal test, CFD, and experimental analysis. Adv Mech Eng, 11 (1-10), 2014.

4. ZHANG W.N. Water Network Design and Management via Stochastic Programming. University of Arizona, 2013.

5. JING L., CHEN B., YE X., ZHANG B.. Wastewater Treatment Plant Network Design Using a Multiscale TwoStage Mixed Integer Stochastic Model. Environmental Engineering Science, 34 (861-871), 2017.

6. MARCHIONNI V., LOPES N., MAMOUROS L., COVAS D. Modelling sewer systems costs with multiple linear regression. Water Resour Manag, 28 (4415-4431), 2014. Valentina. 
7. MOEINI R., AFAHAR M.H. Sewer network design optimization problem using ant colony optimization algorithm and tree growing algorithm. Springer International Publishing, 227 (91-105), 2013.

8. PENG Z.E. LUO J.P., ZHANG X. The optimized model of town sewage structure charge and its computing. Advanced Materials Research, (726-731), 2013.

9. AFSHAR M.H., ROHANI M. Optimal design of sewer networks using cellular automata-based hybrid methods: discrete and continuous approaches. Eng Optim, 44 (1-22), 2012.

10. BERNAT J.D., CARLOS O.M., GABRIELA C. Hybrid modeling and receding horizon control of sewer networks. Water Res Res, 50 (8497-8514), 2014.

11. DUQUE N., DUQUE D., SALDARRIAGA J. Dynamic Programming Over a Graph Modeling Framework for the Optimal Design of Pipe Series in Sewer Systems, Procedia Engineering, 186, (61-68), 2017.

12. HAGHIGHI A., BAKHSHIPOUR A.E. Optimization of sewer networks using an adaptive genetic algorithm. Water Res Manag, 26 (3441-3456), 2012.

13. HAGHIGHI A. Intelligent optimization of wastewater collection networks. Intelligence Systems in Environmental Management: Theory and Applications, 113 (41-65), 2016.
14. ZHOU L., SHI W.D., LU W.G. Orthogonal test design and numerical simulation of 100QJ10 type deep-well pump. Applied Mechanics \& Materials, (110-116), 2011.

15. LEON S.L. Optimization theory for large systems. Dover Publications, 2013.

16. YIN S., LI X., LUO W., SUN M., JING Y. Optimal design of city sewage pipe network layout using the gradient screening enumeration method. Shenyang Jianzhu Daxue Xuebao, 30 (705-711), 2014

17. WANG W.F., CHENG J.L., GONG Y. Optimization on long-distance water supply pipeline based on decomposition-dynamic programming aggregation method. Journal of Irrigation and Drainage, 6, 2013.

18. JIA B.Y., ZHONG P.A., WAN X.Y., XU B., CHEN J. Decomposition-coordination model of reservoir group and flood storage basin for real-time flood control operation. Hydrology Research, 46 (11-25), 2015.

19. LI C.L., ZHOU J.Z., OUYANG S., WANG C., LIU Y. Water resources optimal allocation based on large-scale reservoirs in the upper reaches of Yangtze River. Water Resour Manag, 29 (2171-2187), 2015. 